\title{
Optimization of cultivation conditions for Microcystis aeruginosa for biodiesel production using response surface methodology
}

\author{
Samar A. El-Mekkawi ${ }^{1 *}$ (D, N. N. El-lbiari ${ }^{1}$, Ola A. El-Ardy ${ }^{1}$, Nabil M. Abdelmonem², Ahmed H. Elahwany²,
} Magdi F. Abadir ${ }^{2}$ and Ibrahim M. Ismail ${ }^{3}$

\begin{abstract}
Background: Biodiesel is expected to play a key role in the development of a sustainable, economical, and environmentally safe source of energy. The third generation of biodiesel is derived from microalgae and cyanobacteria that have sufficient amount of oil. The optimization of biomass and oil content in biodiesel production based on algal cultivation relies upon several factors. The present experimental work aims at optimizing some of the cultivation conditions to obtain maximum oil and biomass yield and create a prediction model that describe the effect of the initial inoculum concentration, and irradiance on the biomass yield and oil concentration were designed using Design Expert 6.0.8.

Results: The results revealed that the optimum surface-to-volume ratio for the airlift bubble column photobioreactor was 0.9, and the most applicable model for describing Microcystis aeruginosa growth was the hyperbolic tangent model with a model constant value of $1.294 \mathrm{mg} \cdot \mathrm{L}^{-1} \cdot \mathrm{d}^{-1} / \mu \mathrm{mol} \cdot \mathrm{m}^{-2} \cdot \mathrm{s}^{-1}$. The optimum cultivation conditions were $81 \mathrm{\mu mol} \cdot \mathrm{m}^{-2} \cdot \mathrm{s}^{-1}$ irradiance and $67 \mathrm{mg} \cdot \mathrm{L}^{-1}$ initial inoculum concentration, and these conditions achieved a biomass yield of $163 \mathrm{mg} \cdot \mathrm{L}^{-1} \cdot \mathrm{d}^{-1}$ and an oil concentration of $143 \mathrm{mg} \cdot \mathrm{L}^{-1}$.

Conclusions: This work focused on the cultivation of microalgae in closed systems. Cyanobacteria as M. aeruginosa has high lipid content, and high lipid productivity makes it suitable as a lipid feed stock for biodiesel production. The response surface method was the most suitable route to study the simultaneous influence of irradiance and initial inoculum concentration through statistical methods as well as to establish a model for predicting the biomass yield and oil concentration of M. aeruginosa.
\end{abstract}

Keywords: Factorial design, Photobioreactor, Kinetic models, Biomass, Oil content

\section{Background}

Microalgae are considered a potential source for biodiesel production. Lipids and fatty acids are the major constituents in algal cells (Lyon and Mock 2014). The major part of non-polar lipids (neutral lipids) of microalgae consists of triglycerides (TAGs) which can be used for biodiesel production (Fahy et al. 2009; Sanchez et al. 2011). Like higher plants, microalgal growth is affected

\footnotetext{
* Correspondence: samarelmekkawi@hotmail.com

${ }^{1}$ Chemical Engineering and Pilot Plant Department, National Research

Centre, Giza 12622, Egypt

Full list of author information is available at the end of the article
}

by light capture, the carbon dioxide-to-oxygen ratio, and temperature (Araujo and Garcia 2005; Wang et al. 2012; Zheng et al. 2011), as well as the $\mathrm{pH}$ and mixing speed (Hargreaves and Whitton 1976; Janssen et al. 2000). Additionally, because microalgae are cultivated in an aquatic environment, the sterility and cleanliness of the closed cultivation system itself should be considered to avoid contamination (Posten 2009). The synthesis and accumulation of large amounts of TAGs are accompanied by a considerable alteration in the lipid and fatty acid composition in the cell, which occurs when algae are placed under stressful conditions imposed by chemical 
stimuli, such as nutrient depletion, or physical environmental stimuli, such as the light intensity, either individually or in combination (Widjaja 2009).

The effect of light intensity varies according to the algal species and strains (Schulze et al. 2014). With few exceptions, low light intensity favors the formation of polyunsaturated fatty acids (PUFAs), which in turn are incorporated into the membrane structure (Cuellar-Bermudez et al. 2015). However, elevated light intensities alter fatty acid synthesis by producing more saturated and monounsaturated fatty acids, which are the major components of neutral lipids (Ogbonda et al. 2007). Moreover, photoinhibition may occur because of the overproduction of reactive oxygen species synthesized at the elevated light intensity, and these species damage membrane lipids, proteins, and other macromolecules (Zhu et al. 2008).

In this work, the four strains Scenedesmus obliquus (green algae), Nannochloropsis sp. (genus of algae), Spirulina platensis (cyanobacteria), and Microcystis aeruginosa (cyanobacteria) were cultivated phototrophically and examined to select the strain most suited for biodiesel production. In addition, the optimum illuminated area-to-culture volume ratio was obtained to define the specifications of the bubble column photobioreactor. A set of experiments were run based on the cultivation of $M$. aeruginosa at irradiances ranging from 20.3 to $176 \mu \mathrm{mol} \cdot \mathrm{m}^{-2} \cdot \mathrm{s}^{-1}$ to define the best model for describing the relationship between the algal growth rate and irradiance. Finally, two independent variables that affect algal growth were investigated to optimize the cultivation conditions and model the algal growth: irradiance, and initial inoculum concentration. Although most previous studies have indicated that these parameters affect microalgae growth, one of the two parameters was invariably kept constant while the other was varied which eliminated the possibility of detecting potential interactions between the two factors (Wang et al. 2012). Thus, designing experiments using the Response surface methodology (RSM) allows for the study of the simultaneous influence of several parameters using statistical methods. One of the merits of this system is the possibility of determining any nonlinear relationships between independent variables (Montgomery 2003). This step was enhanced by establishing a model to predict the biomass yield and oil concentration of the selected microalgae species.

\section{Material and methods}

\section{Inoculum preparation and cultivation system}

The microalgae strains were cultivated at a temperature of $20 \pm 1{ }^{\circ} \mathrm{C}$, aeration flow rate of $1 \mathrm{~V} / \mathrm{V}$ and irradiance of $20.3 \mu \mathrm{mol} \cdot \mathrm{m}^{-2} \cdot \mathrm{s}^{-1}$ of white cool fluorescent light for 10 days in flasks using BG11 medium. The inoculum concentration was defined for each strain depending on the chlorophyll content, which was determined via methanol extraction (Fogg and Thake 1987). Chlorophyll a is used as an algal biomass indicator, and its constituents are on the average, $1.5 \%$ of the dry weight of organic matter of algae (Association APHA 1915). Microalgae were harvested via settling without additives for (30-60 min), and the aeration and irradiance cultivation conditions accelerate the growth rate and increase the $\mathrm{pH}$ to 10.5 by the end of the cultivation period, thereby facilitating settling without additives. The sediments were collected and washed twice with water and then centrifuged at $3000 \mathrm{rpm}$ for $10 \mathrm{~min}$. The algal cells were dried at $60{ }^{\circ} \mathrm{C}$ overnight. Oil was extracted from dried weighed samples using hexane and isopropanol in a ratio of 3:2 according to the method applied by Halim et al. (2012); $300 \mathrm{~mL}$ of the mixture was added to $4 \mathrm{~g}$ of microalgae powder; and the mixture of algal powder and solvents was homogenized at $800 \mathrm{rpm}$ for $10 \mathrm{~min}$ to rupture the cell wall. The extraction process was applied at $40{ }^{\circ} \mathrm{C}$ for $2 \mathrm{~h}$, and the mixture was filtered. The filtrate was washed with water to allow the miscible solution to separate according to polarity.

\section{Strain selection}

The four isolated strains of S. platensis, S. obliquus, Nannochloropsis sp., and $M$. aeruginosa were supplied by the Water Pollution Research Department, Environmental Research Division, National Research Centre in Cairo, where the toxicity test of using microcystin was applied to $M$. aeruginosa because certain species of Microcystis are toxic. The four strains were cultivated using BG11 medium in an airlift bubble column photobioreactor (PBR, as shown in Fig. 1) at a temperature of $20 \pm 1{ }^{\circ} \mathrm{C}$, aeration flow rate of 1 $V / V$ and irradiance of $20.3 \mu \mathrm{mol} \cdot \mathrm{m}^{-2} \cdot \mathrm{s}^{-1}$ for 10 days. After harvesting, the oil concentration and biomass yield of the four strains were compared to select the most suitable strain for oil production.

\section{Optimization of PBR dimensions and cultivation conditions}

The PBR design is based on optimizing the parameters that affect microalgae growth. The main parameter that maximizes algal growth is capturing optimal light, which implies a high illuminated surface area/culture volume ratio (S/V) (Richmond 2004). Thus, four duplicated experiments at various $\mathrm{S} / \mathrm{V}$ ratios $(1.8,0.9,0.63$, and 0.48$)$ using the previous cultivation conditions were performed to optimize the biomass yield.

\section{Selected models describing the algal growth kinetics}

The biomass yield can be expressed as the photosynthetic yield, which can be predicted by growth models. Each species has its own growth characteristics, which differ from that of the others. Thus, the optimal growth 


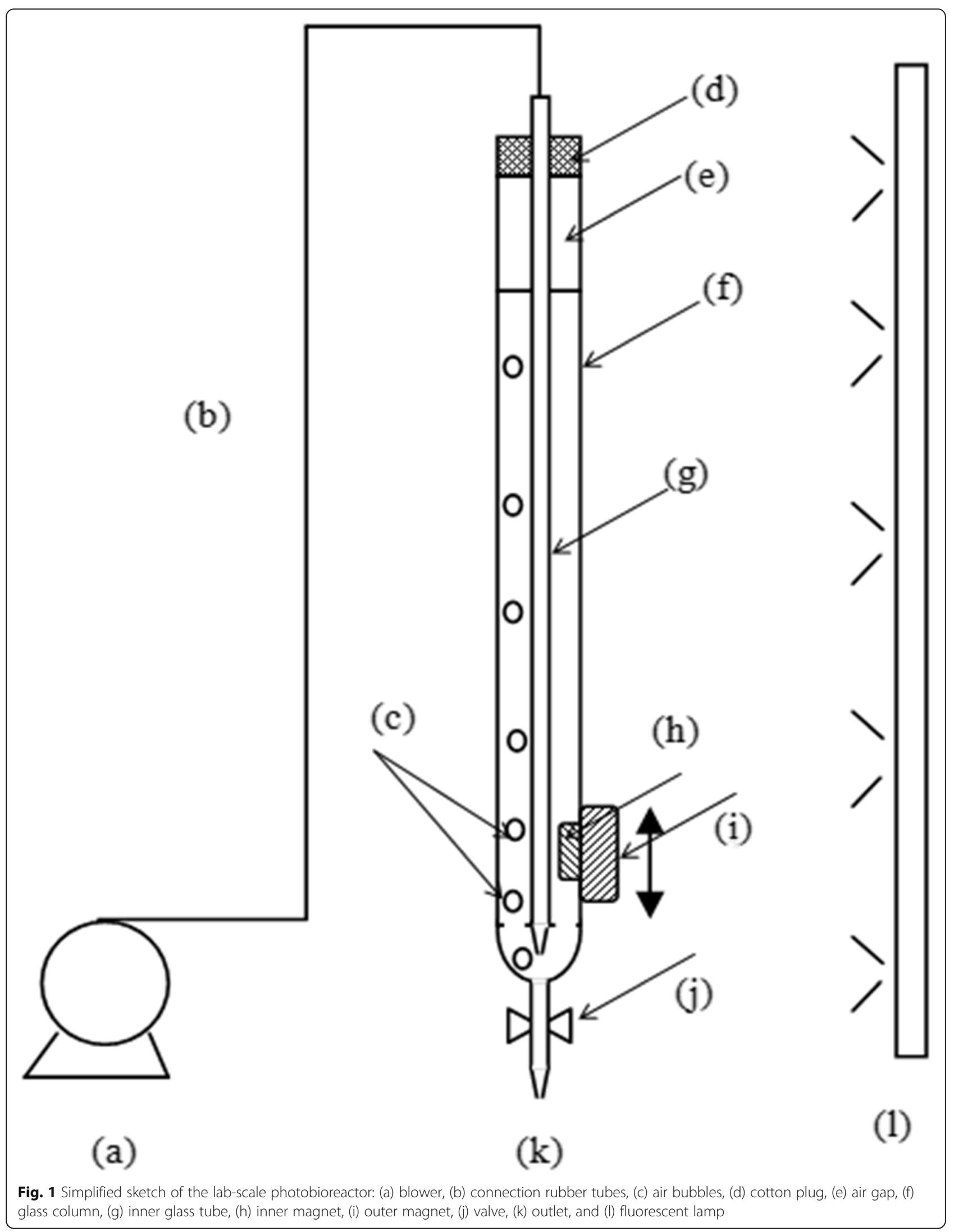


model for describing the selected strain $M$. aeruginosa must be identified. One such model is the hyperbolic tangent model (Kurano and Miyachi 2005):

$$
P=P_{\max } \cdot \tanh (\alpha I)
$$

where

$P$ represents the growth rate $\left(\mathrm{mg} \cdot \mathrm{L}^{-1} \cdot \mathrm{d}^{-1}\right)$;

$I$ represents the irradiance $\left(\mu \mathrm{mol} \cdot \mathrm{m}^{-2} \cdot \mathrm{s}^{-1}\right)$; and

$\alpha$ is the model constant, which was obtained experimentally $\left(\mathrm{mg} \cdot \mathrm{L}^{-1} \cdot \mathrm{d}^{-1} / \mu \mathrm{mol} \cdot \mathrm{m}^{-2} \cdot \mathrm{s}^{-1}\right)$.

The second model is the Monod model (Jalalizadeh 2012; Kurano and Miyachi 2005; Perez et al. 2008; Sundstrom and Klei 1979; Tamiya 1951), which expresses the growth rate in the following form:

$$
\mu=\mu_{\max } I /\left(I+K_{I}\right)
$$

where

$\mu$ represents the specific growth rate $\left(\mathrm{d}^{-1}\right)$;

$I$ represents the irradiance $\left(\mu \mathrm{mol} \cdot \mathrm{m}^{-2} \cdot \mathrm{s}^{-1}\right)$; and

$K_{I}$ is the model constant, which was obtained experimentally $\left(\mu \mathrm{mol} \cdot \mathrm{m}^{-2} \cdot \mathrm{s}^{-1}\right)$.

The third model is a modified Monod model that considers light irradiances as the substrate (Bechet et al. 2013; Jeon et al. 2005):

$$
P=P_{\max } I /\left(I+I_{k}\right)
$$

where

$I_{k}$ is the saturated light intensity $\left(\mu \mathrm{mol} \cdot \mathrm{m}^{-2} \cdot \mathrm{s}^{-1}\right)$.

The experimental data and constants obtained from eight duplicated runs at irradiance values ranging from 20.3 to $176 \mu \mathrm{mol} \cdot \mathrm{m}^{-2} \cdot \mathrm{s}^{-1}$ were used to verify the most applicable model for the selected algal strain. The three models were evaluated by calculating the absolute average deviation (AAD) in the following form (Mejia et al. 2013):

$$
\mathrm{AAD}=(1 / N) \sum \mid(\text { Act.-Pred. }) / \text { Act. } \mid
$$

where

$A A D$ means absolute average deviation;

Act. means actual value;

Pred. means predicted value; and

$N$ means number of set values.

Effect of irradiance and initial inoculum concentration on the biomass yield of $M$. aeruginosa and oil concentration The irradiance and initial inoculum concentration are considered the most significant parameters affecting algal growth that obey phototrophic cultivation (Posten 2009). The range of the examined irradiance was 27$81 \mu \mathrm{mol} \cdot \mathrm{m}^{-2} \cdot \mathrm{s}^{-1}$, and the maximum value of irradiance was determined from the photosynthetic yield-irradiance relation ( $\mathrm{P}-\mathrm{I}$ curve) via the intersection between the initial tangent of the curve and the maximum photosynthetic rate. A dense culture retards light penetration via the PBR wall (Bezerra et al. 2011; Coles and Jones 2000; Jeon et al. 2005). Thus, a range of inoculum concentrations (15.5-67 mg biomass/L) was selected for study. The RSM was chosen as a suitable route for optimizing the interactive effect of irradiance $(I)$ and the initial inoculum concentration $(C)$ on the oil concentration and biomass yield (Montgomery 2003; Silva et al. 2013). The experimental results were statistically analyzed and modeled using the RSM according to Eq. 5 (Montgomery 2003), which was applied using Design Expert-6.0.8 software during a trial period. The extent of the fit of the model was evaluated using the coefficient of determination and analysis of variance (ANOVA).

$$
\begin{aligned}
Y= & a_{0}+a_{1} X_{1}+a_{2} X_{2}+a_{11} X_{1}^{2}+a_{22} X_{2}^{2} \\
& +a_{12} X_{1} X_{2}
\end{aligned}
$$

where

$a_{0}=$ the regression constant;

$a_{0}, a_{1}, a_{2}, a_{11}, a_{22}, a_{12}=$ regression coefficients; and

$X_{1}$ and $X_{2}=$ independent variables investigated here.

\section{Results}

The selection of the most suitable strain for biodiesel production was based on the oil content. The results revealed that the oil contents of Nannochloropsis sp., $S$. platensis, S. obliquus, and M. aeruginosa are $8 \%, 12 \%$, $16 \%$, and $20 \%$, respectively; the lipid productivities are 2 , $4.8,5.6$, and $6 \mathrm{mg} \cdot \mathrm{L}^{-1} \cdot \mathrm{d}^{-1}$, respectively; and the biomass productivities are $25,40,35$, and $30 \mathrm{mg} \cdot \mathrm{L}^{-1} \cdot \mathrm{d}^{-1}$, respectively. $M$. aeruginosa has the highest lipid content and the highest lipid productivity which is desired for biodiesel production. Examining the S/V ratios of 1.8, 0.9, 0.63 , and 0.48 , the results revealed that the biomass yield for $M$. aeruginosa is $23.3,45,42.4$, and $33.8 \mathrm{mg} \cdot \mathrm{L}^{-1} \cdot \mathrm{d}^{-1}$, respectively, and the optimum S/V ratio is 0.9 .

The cell productivities of eight duplicated runs in the range of $20.3-176 \mu \mathrm{mol} \cdot \mathrm{m}^{-2} \cdot \mathrm{s}^{-1}$ at $\mathrm{S} / \mathrm{V}=0.9$ were plotted versus irradiance using Origin 8.5 program Data Analysis and Graphic Software with an adjusted $R^{2}=0.99$. The intersection between the initial tangent $\left(\alpha=1.294 \mathrm{mg} \cdot \mathrm{L}^{-1}\right.$. $\left.\mathrm{d}^{-1} / \mu \mathrm{mol} \cdot \mathrm{m}^{-2} \cdot \mathrm{s}^{-1}\right)$ and maximum cell productivity was observed at the saturation irradiance $\left(I_{k}=85 \mu \mathrm{mol} \cdot \mathrm{m}^{-2}\right.$. $\left.\mathrm{s}^{-1}\right)$. A comparison of the specific growth rates versus irradiance showed that the Monod model constant $\left(K_{I}\right)$ determined at $\mu=\mu_{\max } / 2$ was $12.5 \mu \mathrm{mol} \cdot \mathrm{m}^{-2} \cdot \mathrm{s}^{-1}$ (with adjusted $R^{2}$ of 0.99). This result is consistent with the work of Perez et al. (2008), where an adjustment of data was performed via a reciprocal linear regression to obtain a constant of $K_{I}=10.2 \mu \mathrm{mol} \cdot \mathrm{m}^{-2} \cdot \mathrm{s}^{-1}$ and $R^{2}=0.95$.

The three models were compared statistically using the AAD. The hyperbolic tangent model was the optimal model for describing $M$. aeruginosa growth because the AAD was 0.058 , while the AADs of the Monod model 
Table 1 Evaluation of three kinetic models

\begin{tabular}{|c|c|c|c|c|c|c|c|c|c|}
\hline \multirow{2}{*}{$\begin{array}{l} \\
(\mu \mathrm{mol} / \\
\left.\mathrm{m}^{2} \cdot \mathrm{s}\right)\end{array}$} & \multicolumn{3}{|c|}{$\mu=\mu_{\max } \cdot I /(I+K)$} & \multicolumn{3}{|c|}{$P=P_{\max } \cdot I /\left(I+I_{k}\right)$} & \multicolumn{3}{|c|}{$P=P_{\text {max }} \cdot \tanh (a l)$} \\
\hline & $\mu_{\text {Act. }}$ & $\mu_{\text {pred. }}$ & $\mu_{\mathrm{AAD}}$ & $P_{\text {Act. }}$ & $P_{\text {pred. }}$ & $P_{A A D}$ & $P_{\text {Act. }}$ & $P_{\text {pred. }}$ & $P_{\mathrm{AAD}}$ \\
\hline 20.3 & 0.25 & 0.223 & 0.109 & 25 & 21.206 & 0.152 & 25 & 25.782 & 0.031 \\
\hline 33.8 & 0.312 & 0.263 & 0.158 & 45 & 31.296 & 0.305 & 45 & 41.573 & 0.076 \\
\hline 47.2 & 0.34 & 0.285 & 0.163 & 59 & 39.274 & 0.334 & 59 & 55.493 & 0.059 \\
\hline 74.3 & 0.352 & 0.308 & 0.125 & 82 & 51.306 & 0.374 & 82 & 77.381 & 0.056 \\
\hline 87.8 & 0.353 & 0.315 & 0.107 & 92 & 55.891 & 0.392 & 92 & 85.259 & 0.073 \\
\hline 115 & 0.359 & 0.325 & 0.096 & 104.7 & 63.25 & 0.396 & 104.7 & 96.222 & 0.081 \\
\hline 149 & 0.36 & 0.332 & 0.077 & 110 & 70.043 & 0.363 & 110 & 103.588 & 0.058 \\
\hline 176 & 0.36 & 0.336 & 0.066 & 110 & 74.176 & 0.326 & 110 & 106.556 & 0.031 \\
\hline$A A D$ & & & 0.113 & & & 0.330 & & & 0.058 \\
\hline
\end{tabular}

Specific growth rate $(\mu)$, cell productivity $(P)$, actual values (Act.), predicted values (Pred.), absolute average deviation (AAD), and irradiance (I)

and Modified Monod model were 0.113 and 0.33 , respectively (Table 1). The hyperbolic tangent function provided the best fit, as evaluated by the extended information criterion (EIC).

The effects of irradiance and initial inoculum concentration were studied as two independent variables affecting biomass yield and oil concentration in a total of 13 experiments in accordance with a 22 complete factorial design as shown in Table 2. The data were analyzed using Design Expert 6.0.8 software and by applying the RSM. Table 3 describes the ANOVA for the response surface of a quadratic model for oil concentration response and biomass yield. A statistical analysis of the oil concentration response revealed that the predicted $R^{2}$ was 0.99 and the adjusted $R^{2}$ was 0.99 , whereas an analysis of the yield response revealed that the predicted $R^{2}$ and the adjusted $R^{2}$ were 0.98 and 0.96 , respectively. The coefficients of variation (CVs) of the oil concentration response and yield response were 3.19 and 1.58 , respectively. The analysis yielded two linear coefficients $(A, B)$, two quadratic coefficients $\left(A^{2}, B^{2}\right)$, and one cross-product coefficient for the full model.

Both the adjusted and predicted coefficients of determination $\left(R^{2}\right)$ were approximately 0.99 , indicating that the model is highly reliable. Equations 6, 7, 8 and 9 represent the final estimated response model equations of biomass yield and oil concentration in terms of the coded and actual values.

The regression equation for the percent biomass yield in terms of coded variables is as follows:

$$
\begin{aligned}
\text { Yield }= & 96.4+(34.04 \times A) \\
& +(31.03 \times B)-(2.07 \times A)-\left(4.57 \times C^{2}\right) \\
& +(7.00 \times A \times B)
\end{aligned}
$$

The regression equation of the biomass yield response

\begin{tabular}{|c|c|c|c|c|c|c|c|c|}
\hline \multirow[t]{2}{*}{ Run } & \multirow[t]{2}{*}{$A$} & \multirow[t]{2}{*}{$B$} & \multirow{2}{*}{$\begin{array}{l}\text { l } \\
(\mathrm{k} \mid x)\end{array}$} & \multirow{2}{*}{$\begin{array}{l}\mathrm{C} \\
(\mathrm{mg} / \mathrm{L})\end{array}$} & \multicolumn{2}{|c|}{ Oil concentration (mg/L) } & \multicolumn{2}{|c|}{ Biomass yield $(\mathrm{mg} / \mathrm{L} \cdot \mathrm{d})$} \\
\hline & & & & & Actual & Predicted & Actual & Predicted \\
\hline 1 & 0 & $-a$ & 4.00 & 4.83 & 60.00 & 56.52 & 45.00 & 43.37 \\
\hline 2 & -1 & -1 & 2.00 & 15.50 & 49.00 & 52.42 & 30.00 & 31.68 \\
\hline 3 & 0 & 0 & 4.00 & 41.25 & 107.80 & 105.76 & 98.00 & 96.40 \\
\hline 4 & +1 & +1 & 6.00 & 67.00 & 143.00 & 140.08 & 163.00 & 161.82 \\
\hline 5 & +1 & -1 & 6.00 & 15.50 & 78.00 & 79.65 & 85.00 & 85.77 \\
\hline 6 & 0 & $+a$ & 4.00 & 77.67 & 110.00 & 112.98 & 130.00 & 131.13 \\
\hline 7 & 0 & 0 & 4.00 & 41.25 & 106.00 & 105.76 & 96.00 & 96.40 \\
\hline 8 & 0 & 0 & 4.00 & 41.25 & 105.00 & 105.76 & 96.00 & 96.40 \\
\hline 9 & 0 & 0 & 4.00 & 41.25 & 103.00 & 105.76 & 95.00 & 96.40 \\
\hline 10 & -1 & +1 & 2.00 & 67.00 & 73.00 & 71.87 & 80.00 & 79.73 \\
\hline 11 & $-a$ & 0 & 1.17 & 41.25 & 55.00 & 53.50 & 45.00 & 44.10 \\
\hline 12 & 0 & 0 & 4.00 & 41.25 & 107.00 & 105.76 & 97.00 & 96.40 \\
\hline 13 & $+a$ & 0 & 6.83 & 41.25 & 120.00 & 121.00 & 140.00 & 140.40 \\
\hline
\end{tabular}
in terms of the actual variables is as follows:

Table 2 Experimental data for five levels of the two-factor response surface analysis

Irradiance as the coded variable $(A)$, and initial inoculum as the coded variable $(B)$ 
Table 3 ANOVA results for the response surface quadratic model

\begin{tabular}{llllll}
\hline Source & \multicolumn{2}{l}{ Biomass yield response } & & \multicolumn{2}{l}{ Oil concentration response } \\
\cline { 2 - 3 } & F-value & Prob $>F$ & & $F$-value & Prob $>F$ \\
\hline Model & 1622.41 & $<0.0001$ & & 209.87 & $<0.0001$ \\
$A$ & 4340.12 & $<0.0001$ & & 510.14 & $<0.0001$ \\
$B$ & 3604.77 & $<0.0001$ & & 356.97 & $<0.0001$ \\
$A^{2}$ & 14.02 & 0.0072 & & 66.71 & $<0.0001$ \\
$B^{2}$ & 68.16 & $<0.0001$ & & 85.95 & $<0.0001$ \\
A & 91.75 & $<0.0001$ & & 47.05 & 0.0002 \\
Lack of fit & 2.50 & 0.1984 & & 4.64 & 0.0861 \\
\hline
\end{tabular}

$$
\begin{aligned}
\text { Yield }= & -19.00271+(15.5651 \times I)+(1.23044 \times C)-\left(0.51875 \times I^{2}\right) \\
& -\left(6.8998 \times 10^{3} \times C^{2}\right)+(0.1352 \times I \times C)
\end{aligned}
$$

The corresponding equation for the percent oil concentration in terms of coded variables is as follows:

$$
\begin{aligned}
\text { Oil concentration }=105.76 & +(23.87 \times A)+(19.96 \times B)-\left(9.25 \times A^{2}\right) \\
& -\left(10.50 \times B^{2}\right)+(10.25 \times A \times B)
\end{aligned}
$$

The regression equation of the oil concentration response in terms of the actual variables is as follows:

$$
\begin{aligned}
\text { Oil concentration }=-5.09018 & +(22.23279 \times I)+(1.28624 \times C) \\
& -\left(2.31375 \times I^{2}\right)-\left(0.015843 \times C^{2}\right) \\
& +(0.19903 \times I \times C)
\end{aligned}
$$

Figures 2 and 3 illustrate a plot of the experimental values versus predicted values for the biomass yield and oil concentration response respectively. The response values predicted from the empirical model are consistent with the actual values over the selected range of operation indicating that the model adequately represents the experimental data. The surface plot and contours of the oil concentration and the biomass yield versus the irradiance and the initial inoculum concentration obtained when individual experimental data were plotted are shown in Figs. 4 and 5. The RSM model equation revealed that biomass yield increases as both the irradiance and initial concentration increase. The results also indicated that the optimum yield and oil concentration can be obtained at $81 \mu \mathrm{mol} \cdot \mathrm{m}^{-2} \cdot \mathrm{s}^{-1}$ irradiance and $67 \mathrm{mg} \cdot \mathrm{L}^{-1}$ initial concentration. The predicted biomass yield and oil concentration were $161.82 \mathrm{mg} \cdot \mathrm{L}^{-1} \cdot \mathrm{d}^{-1}$ and 140.079 $\mathrm{mg} \cdot \mathrm{L}^{-1}$, respectively, whereas the actual values were $163 \mathrm{mg} \cdot \mathrm{L}^{-1} \cdot \mathrm{d}^{-1}$ and $143 \mathrm{mg} \cdot \mathrm{L}^{-1}$, respectively.

\section{Discussion}

The results for the oil content of $M$. aeruginosa are close to those obtained by Sharathchandra and Rajashekhar (2011) who found that the percentage of extracted oil based on biomass was $28.15 \pm 2 \%$, which was also confirmed by the work of El-Ardy et al. (2012). However, the higher percentage obtained by the latter authors could be attributed to the high-temperature range used $\left(20-30{ }^{\circ} \mathrm{C}\right)$. The results achieved by Da Ros et al. (2013) are also close to reported research: the lipid productivity was $3.1 \mathrm{mg} \cdot \mathrm{L}^{-1}$. $\mathrm{d}^{-1}$, and biomass productivity was $46.9 \mathrm{mg} \cdot \mathrm{L}^{-1} \cdot \mathrm{d}^{-1}$. In the present work, the corresponding results are $6 \mathrm{mg} \cdot \mathrm{L}^{-1} \cdot \mathrm{d}^{-1}$ lipid productivity and $30 \mathrm{mg} \cdot \mathrm{L}^{-1} \cdot \mathrm{d}^{-1}$ biomass productivity. M. aeruginosa was selected according to its sufficient oil content and simple cell structure, which can be easily ruptured during oil extraction using chemical methods.

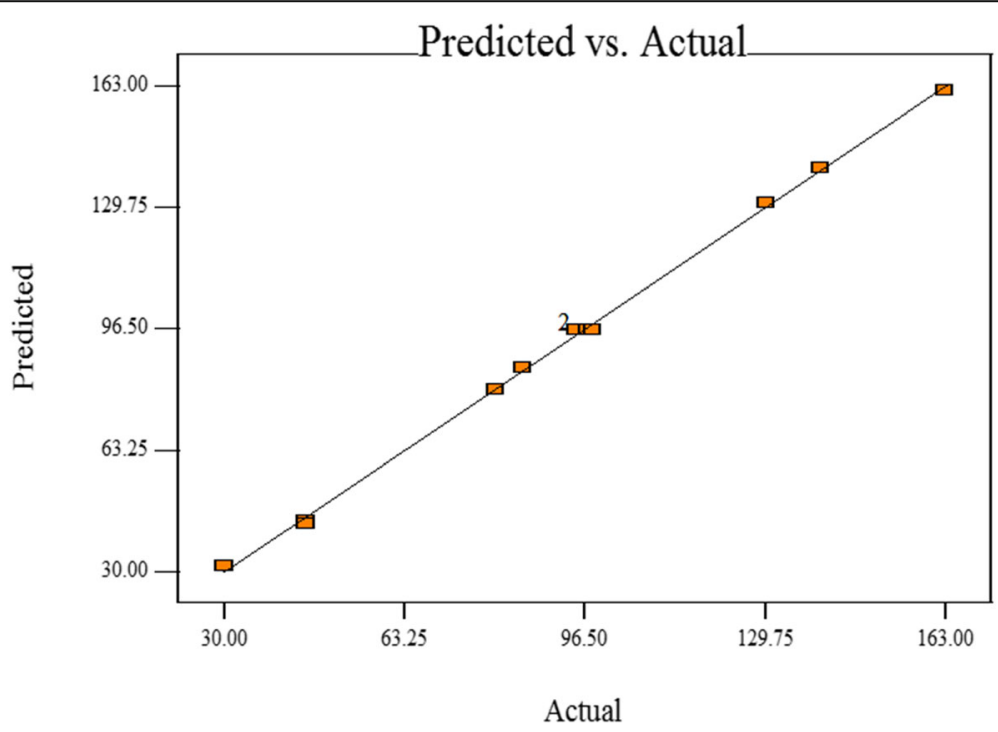

Fig. 2 Actual biomass yield values vs. predicted RSM model 


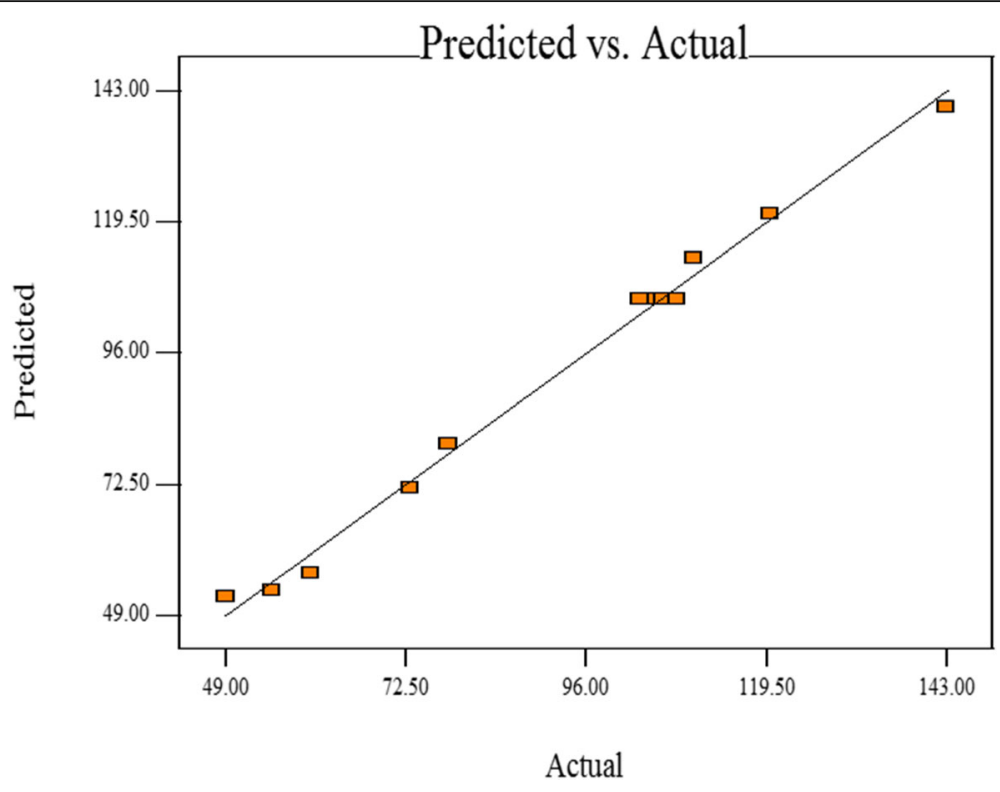

Fig. 3 Actual oil concentration values vs. predicted RSM model

The optimum ratio of illuminated surface area to volume obtained was 0.9. This result is consistent with the work of Richmond (2004), who recommended using a ratio approaching, but not exceeding, unity. The specific nature of algae differs among species according to the nature of the strain thus, the constants of each examined model had to be obtained experimentally and the models of $M$. aeruginosa had to be obtained specifically. The hyperbolic tangent function applied to $M$. aeruginosa provided the best fit, as evaluated by the EIC. This model is necessary to study the relationship between irradiance and growth rate which will enhance further studies on other dependent variables related to irradiance.

Finally, the interactive effect of irradiance and the initial inoculum concentration on the oil concentration and biomass yield was investigated using the RSM. The statistical analysis of each yield response and oil concentration response revealed that the predicted $R^{2}$ and adjusted $R^{2}$ are similar. In addition, high variance was observed because the $\mathrm{CV}$ was greater than one, indicating that the data points distributed at a distance from the mean, and from one another. The $F$-value test was applied to both the oil concentration model and biomass yield model. These models were found to be statistically significant based on an error analysis. The probability test revealed that the models' terms are significant. Model verification was enhanced based on the non-significance of the lack of fit, which indicates non-significant error and suggests that the model can accurately predict the relationships between the reaction factors in the selected range.

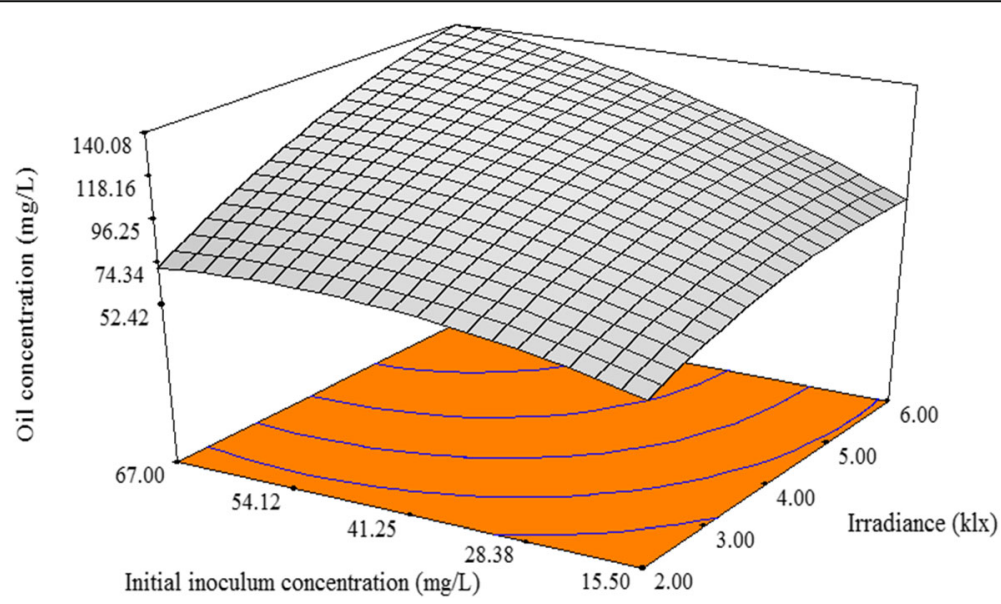

Fig. 4 RSM model graph of the oil concentration response 


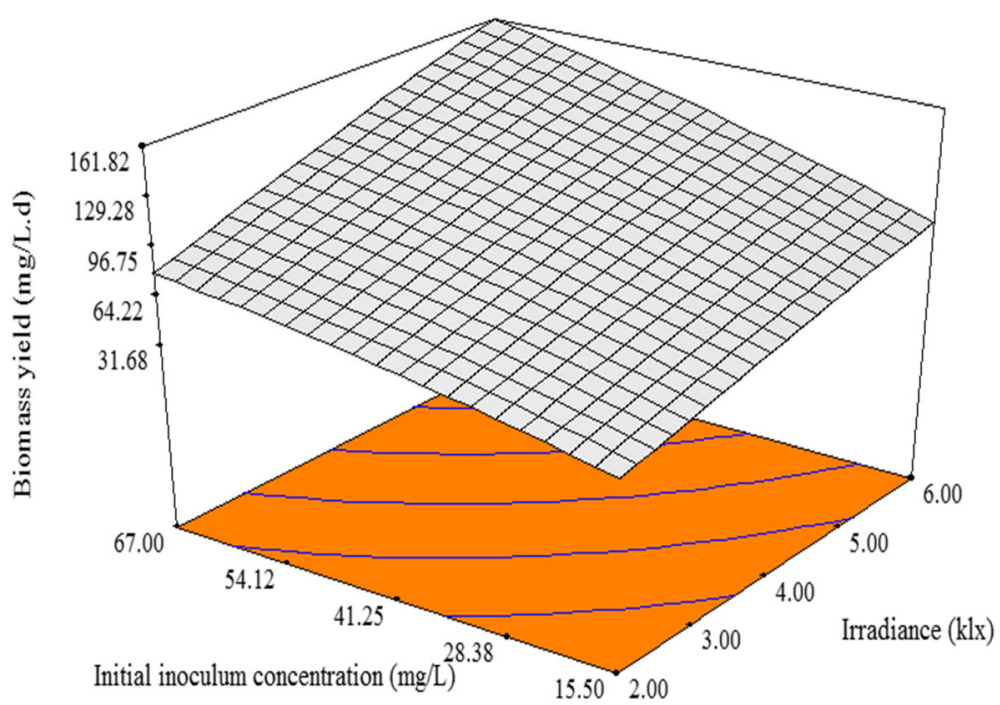

Fig. 5 RSM model graph of the biomass yield response

\section{Conclusions}

This work focused on the cultivation of microalgae in closed systems because open ponds are inexpensive but vulnerable to environmental disturbances, such as temperature swings and biological invasions. $M$. aeruginosa has various advantages as a lipid feed stock for biodiesel production, compared with two strains of algae (S. obliquus, and Nannochloropsis $s p$.) and a cyanobacterium strain (S. platensis), which were locally isolated and cultivated strains. These benefits included a high lipid content and high lipid productivity. In general, the microalgae growth rate or productivity can be predicted using models of algal growth. The hyperbolic tangent model $p=p_{\text {max }} \cdot \tanh (\alpha I)$ describes the relationship between irradiance and the growth rate of $M$. aeruginosa. The RSM was used to study the simultaneous influence of two independent variables through statistical methods to optimize these variables, irradiance and initial inoculum concentration, as well as to establish a model for predicting the biomass yield and oil concentration of $M$. aeruginosa. Further research is required to improve the models and simultaneously study more factors using $\mathrm{CO}_{2}$. The main target of such studies is to convert these batch processes into a continuous cultivation system with minimal cost and effort.

\section{Abbreviations}

AAD: Asolute average deviation; C: Inoculum concentration (g/L); CVs: Coefficients of variation; EIC: Information criterion; I: Irradiance $\left(\mu \mathrm{mol} \cdot \mathrm{m}^{-2} \cdot \mathrm{s}^{-1}\right) ; l_{k}$ : Saturated light intensity $\left(\mu \mathrm{mol} \cdot \mathrm{m}^{-2} \cdot \mathrm{s}^{-1}\right) ; K_{i}$ : Model constant $\left(\mu \mathrm{mol} \cdot \mathrm{m}^{-2} \cdot \mathrm{s}^{-1}\right) ;$ P: Growth rate $\left(\mathrm{mg} \cdot \mathrm{L}^{-1} \cdot \mathrm{d}^{-1}\right)$; PBR: Photobioreactor; PUFAs: Polyunsaturated fatty acids; RSM: Response surface methodology; S/ V: Illuminated surface area/culture volume ratio; TAGs: Triglycerides; $a$ : Model constant $\left(\mathrm{mg} \cdot \mathrm{L}^{-1} \cdot \mathrm{d}^{-1} / \mu \mathrm{mol} \cdot \mathrm{m}^{-2} \cdot \mathrm{s}^{-1}\right)$; $\mu$ : Specific growth rate $\left(\mathrm{d}^{-1}\right)$;

\section{Acknowledgments}

The authors would like to acknowledge Prof. Gamila Ali, Water Pollution Department, National Research Centre, Egypt, for providing them the algal strains studied in this work.

\section{Authors' contributions}

SEM and OEA performed the experimental work. NNEI performed the statistical analysis. MA revised the statistical analysis part and was a major contributor in writing the manuscript. NA, AE, and II analyzed and revised the results. All authors read and approved the final manuscript.

\section{Funding}

This work was done in the National Research Centre, Egypt that has funded all the experimental work.

\section{Availability of data and materials}

Not applicable

Ethics approval and consent to participate

Not applicable

\section{Consent for publication}

Not applicable

\section{Competing interests}

The authors declare that they have no competing interests.

\section{Author details}

${ }^{1}$ Chemical Engineering and Pilot Plant Department, National Research Centre, Giza 12622, Egypt. ${ }^{2}$ Chemical Engineering Department, Faculty of Engineering, Giza, Egypt. ${ }^{3}$ Renewable Energy Engineering, Zewail City of Science and Technology, Giza, Egypt.

Received: 12 July 2018 Accepted: 29 December 2019

Published online: 10 January 2020

\section{References}

Araujo S, Garcia VM (2005) Growth and biochemical composition of the diatom Chaetoceros cf. Wighamii Brightwell under different temperature, salinity, and carbon dioxide levels, protein, carbohydrates and lipids. Aquaculture 246: 405-412

Association APHA (1915) Standard methods for the examination of water and wastewater. American Public Health Association 2

Bechet Q, Shilton A, Guieysse B (2013) Modeling the effects of light and temperature on algae growth. State of the art and critical assessment for productivity prediction during outdoor cultivation. Biotechnol Adv 31 : 1648-1663

Bezerra RP, Montoya EYO, Sato S, Perego P, De Carvalho JCM, Converti A (2011) Effects of light intensity and dilution rate on the semi-continuous cultivation 
of Arthrospira (Spirulina) platensis. A kinetics Monod-type approach. Bioresour Technol 102:3215-3219

Coles JF, Jones C (2000) Effect of temperature on photosynthesis light response and growth of four phytoplankton species isolated from a tidal freshwater river. J Phycol 36:7-16

Cuellar-Bermudez SP, Romero-Ogawa MA, Vannela R, Lai YS, Rittmann BE, ParraSaldivar R (2015) Effects of light intensity and carbon dioxide on lipids and fatty acids produced by Synechocystis sp. PCC6803 during continuous flow. Algal Res 12:10-16

Da Ros PCM, Silva CSP, Silva-Stenico ME, Fiore MF, De Castro HF (2013) Assessment of chemical and physico-chemical properties of Cyanobacterial lipids for biodiesel production. Mar Drugs 11:2365-2381

El-Ardy O, Abo El-Enin SA, El Semary NA, El Diwani G (2012) Microalgal culture in photo-bioreactor for biodiesel production: case studies from Egypt. Afinidad 558:137-143

Fahy E, Subramaniam S, Murphy RC, Nishijima M, Raetz CRH, Shimizu T et al (2009) Update of the lipid maps comprehensive classification system for lipids. J Lipid Res 50:S9-S14

Fogg GE, Thake B (1987) Algal cultures and phytoplankton ecology. 3rd ed. University of Wisconsin Press 269-270

Halim R, Danquah MK, Webley PA (2012) Extraction of oil from microalgae for biodiesel production: a review. Biotechnol Adv 30(3):709-732

Hargreaves JW, Whitton BA (1976) Effect of pH on growth of acid stream algae. Br Phycol J 11:215-223

Jalalizadeh M (2012) Development of an integrated process model for algae growth in a photobioreactor. M. Sc Thesis. University of the South Florida

Janssen M, Bresser L, Baijens T, Tramper J, Mur LR, Snel JFH et al (2000) Scale-up aspects of photobioreactors: effects of mixing-induced light/dark cycles. J Appl Phycol 12:225-237

Jeon YC, Cho CW, Yun YS (2005) Measurement of microalgal photosynthetic activity depending on light intensity and quality. Biochem Eng J 27:127-131

Kurano N, Miyachi S (2005) Selection of microalgal growth model for describing specific growth rate-light response using extended information criterion. J Biosci Bioeng The Society for Biotechnology Japan 100(4):403-408

Lyon BR, Mock T (2014) Polar microalgae: new approaches towards understanding adaptations to an extreme and changing environment. Biology 3:56-80

Mejia JD, Salgado N, Orrego CE (2013) Effect of blends of diesel and palmcastor biodiesels on viscosity, cloud point, and flash point. Ind Crop Prod 43:791-797

Montgomery DC (2003) Introduction to factorial design. In: Design and Analysis of Experiments, fifth ed. John Wiley and Sons Inc 170-228

Ogbonda KH, Aminigo RE, Abu GO (2007) Influence of aeration and lighting on biomass production and protein biosynthesis in a Spirulina sp. isolated from an oil-polluted brackish water marsh in the Niger Delta. Nigeria African Journal of Biotechnology 6(22):2596-2600

Perez EB, Pina IC, Rodriguez P (2008) Kinetic model for growth of Phaeodactylum tricornutum in intensive culture photobioreactor. Biochem Eng J 40:520-525

Posten C (2009) Design principles of photobioreactors for cultivation of microalgae. Eng Life Sci 9(3):165-177

Richmond A (2004) Biological principles of mass cultivation. In: Richmond A, eds. Handbook of Microalgal Culture: Biotechnology and Applied Phycology. Blackwell publishing 125-177

Sanchez E, Ojeda K, El-Halwagi M, Kafarov V (2011) Biodiesel from microalgae oil production in two sequential esterification transestrification reactors: pinch analysis of heat integration. Chem Eng J 176-177:211-216

Schulze PS, Barreira LA, Pereira HG, Perales JA, Varela JC (2014) Light emitting diodes (LEDs) applied to microalgal production. Trends Biotechnol 32:422-430

Sharathchandra K, Rajashekhar M (2011) Total lipid and fatty acid composition in some fresh water cyanobacteria. J Algal Biomass 2(2):83-97

Silva CSP, Silva-Stenico ME, Fiore MF, de Castro HF, Da Ros PCM (2013) Optimization of the cultivation conditions for Synechococcus sp. PCC7942 (cyanobacterium) to be used as feedstock for biodiesel production. Algal Res $3(1): 1-7$

Sundstrom DW, Klei HE (1979) Biological mechanisms and kinetics. In: Waste Water Treatment. Prentice-Hall. Engle Wood Clifts, New Jersey 83-88

Tamiya H (1951) Some theoretical notes on the kinetics of algal growth. Bot Mag Tokyo 64:167-173

Wang B, Lan CQ, Horsman M (2012) Closed photobioreactor for production of microalgal biomasses. Biotechnol Adv 30(4):904-912
Widjaja A (2009) Lipid production from microalgae as a promising candidate for biodiesel production. Makara Teknologi 13(1):47-51

Zheng Y, Chen Z, Lu H, Zhang W (2011) Optimization of carbon dioxide fixation and starch accumulation by Tetraselmis subcordiformis in a rectangular airlift photobioreactor. African J Biotechnol 10(10):1888-1901

Zhu XG, Long SP, Ort DR (2008) What is the maximum efficiency with which photosynthesis can convert solar energy into biomass? Curr Opin Biotechnol 19:153-159

\section{Publisher's Note}

Springer Nature remains neutral with regard to jurisdictional claims in published maps and institutional affiliations.

\section{Submit your manuscript to a SpringerOpen ${ }^{\circ}$ journal and benefit from:}

- Convenient online submission

- Rigorous peer review

- Open access: articles freely available online

- High visibility within the field

- Retaining the copyright to your article

Submit your next manuscript at $\boldsymbol{\nabla}$ springeropen.com 